\title{
Estudo da Variação Lexical na Mmazônia Paraense: um olhar sobre o Atlas Linguistico do Brasil
}

\author{
Lexical Study of Variation in the Pará Amazon: \\ A loOK on the Linguistic AtLas of BraziL
}

\section{Sandra Regina FEITEIRO * Socorro Cardoso SILVA **}

Resumo: Este artigo apresenta uma análise das ocorrências semântico-lexicais da fala dos moradores localizados na área rural da Amazônia paraense, em comparação às propostas apresentadas pelo Atlas Linguístico do Brasil (COMITÊ NACIONAL, 2001). Os dados foram coletados in loco através da aplicação do Questionário Semântico-Lexical (QSL), composto de quatorze campos semânticos para quatro informantes desse ponto linguístico. As análises foram feitas com o intuito de dar conta das dimensões diatópica, diagenérica e diageracional da variação ocorrida na fala dos informantes. Este estudo também foi orientado pelos pressupostos teórico-metodológicos da Sociolinguística, da Dialetologia e da Geografia Linguística. Para tanto, recorreu a autores como Cardoso e Ferreira (1994), Aguilera (2005), Brandão (2005) e Labov (2008), dentre outros. Os resultados apresentados em cartas linguísticas demonstram a importância das pesquisas dialetológicas para o conhecimento da norma lexical de um espaço geográfico, apresentando alta produtividade de variantes para um mesmo conteúdo semântico e não coincidentes com as do ALiB.

\footnotetext{
* Mestranda no Programa de Pós-Graduação em Linguística pela Universidade Federal do Pará (UFPA). Professora efetiva de Língua Portuguesa na rede pública do Estado do Pará (SEDUC-PA). Contato: sfeiteiro@gmail.com.

** Doutora em Semiótica e Linguística Geral pela Universidade de São Paulo (2002). Professora Titular e pesquisadora da Universidade da Amazônia (UNAMA) e Professora Titular e pesquisadora da Universidade do Estado do Pará (UEPA). Contato: socorro_cardoso@yahoo.com.br.
} 
Palavras-chave: Dialetologia. Sociolinguística. Variação lexical.

\begin{abstract}
This article presents an analysis of the semantic-lexical occurrences of speech of residents located in rural Pará Amazon, compared to proposals from the Linguistic Atlas of Brazil (COMITÊ NACIONAL, 2001). Data were collected in situ by applying the Semantic-Lexical Questionnaire (QSL), composed of fourteen semantic fields for four informants that linguistic point. Analyzes were made with the intention of fulfilling the diatopical, diageneric and diageracional dimensions the variation in the speech of informants. This study was also guided by theoretical and methodological assumptions of Sociolinguistics, Dialectology and Linguistic Geography. Therefore, the research appealed to authors like Cardoso and Ferreira (1994), Aguilera (2005), Brandão (2005) and Labov (2008), among others. The results presented in language letters show the importance of dialectologies research to the knowledge of lexical norm of a geographic space, with high productivity variants for the same semantic content and not coincident with the Alib.
\end{abstract}

Keywords: Dialectology. Sociolinguistics. Lexical variation.

\title{
Introdução
}

A pesquisa dialetal permite que conheçamos as características e tendências linguístico-culturais importantes para o registro e a valorização da identidade cultural de uma comunidade. Muitas pesquisas sobre variação lexical na língua portuguesa foram realizadas em todo o país, com maior destaque desde a década de noventa com a criação do Comitê Nacional do Atlas Linguístico do Brasil, em 1996. Esses estudos dialetais são relevantes para as pesquisas sociolinguísticas por registrar a língua em seu contexto de uso e também por contribuir com o aprimoramento de métodos para a elaboração de atlas linguísticos. Assim, a escolha do ponto linguístico tornase relevante por ser o Pará o segundo maior estado em extensão do território nacional e por possuir um campo vasto para pesquisas dialetais, tanto no que diz respeito às suas dimensões geográficas quanto à populacional, que é consideravelmente diversificada. 
Vale ressaltar, também, em razão de ser um estudo na perspectiva da geolinguística, a urgência que há em documentar o léxico do português, principalmente dos falares ribeirinhos, com o objetivo de preservar essa diversidade. Com efeito, apresentamos uma análise semântico-lexical de alguns aspectos da fala dos moradores da zona rural paraense em comparação ao proposto pelo Questionário Semântico-Lexical, do Comitê encarregado de elaborar o Atlas Linguístico do Brasil (COMITÊ NACIONAL, 2001).

Situaremos o estudo apresentando conceitos fundamentais para as pesquisas dialetológicas, abordando sucintamente os constructos teóricos da Dialetologia, da Geolinguística e da Sociolinguística, destacando as interfaces existentes entre elas, assim como a importância das pesquisas geolinguísticas para o estudo da distribuição diatópica no aspecto lexical do português falado no Brasil. Em seguida, breve abordagem sobre variação e mudança linguísticas e a metodologia da pesquisa, finalizando com a análise dos dados mostrada por meio de cartas linguísticas.

\section{Abordagem Teórica para o Estudo da Variação Semântico-Lexical}

\subsection{Dialetologia e Sociolinguística}

A partir da década de 1970, muitos estudos surgiram no Brasil na área da Sociolinguística, com a finalidade de investigar a linguagem, relacionandoa aos fatores sociais que diferenciam as comunidades de fala, desconstruindo a ideia de homogeneidade linguística.

Para essa ideia, que integra o funcionamento da linguagem, no tratamento da diversidade linguística, existem duas áreas de estudos afins: i) a Dialetologia, disciplina que tem por objeto de estudo os dialetos, considerados como quaisquer variedades de uma língua; e ii) a Sociolinguística, ciência que também estuda as diferentes formas de uso de uma língua no seio das comunidades de fala, mas cada uma delas com um método de investigação científico particular.

A confluência dessas definições é evidenciada em muitas pesquisas realizadas com o objetivo de identificar tais variedades do português brasileiro de norte a sul do país, mostrando em seus resultados a existência de fronteiras linguísticas diversificadas das fronteiras geográficas, manifestando que essa 
variedade é provocada por diversos fatores, dentre eles os processos migratórios vivenciados no Brasil e que colaboram para a constituição de um falar com características histórico-culturais interessantes à descrição geográfica do léxico brasileiro. A esse respeito, Brandão (2005, p. 5) destaca:

Pode-se afirmar que na língua, se projeta a cultura de um povo, compreendendo-se cultura no sentido mais amplo, aquela que abarca o conjunto dos padrões de comportamento, das crenças, das instituições e de outros valores espirituais e materiais transmitidos coletivamente e característicos de uma sociedade.

Com efeito, Labov (2008) traz o pressuposto básico de que não há língua que não esteja intrinsecamente ligada ao social, uma vez que o próprio nome sociolinguística já é por si só redundante. A sociolinguística é, pois, a ciência que estuda a "relação entre língua e sociedade e na possibilidade, virtual e real, de se sistematizar a variação existente e própria da língua falada", conforme (TARALLO, 2007, p. 7).

Como percebemos, essa concepção é extremamente produtiva para o reconhecimento da variação dialetal existente nas línguas. A sociolinguística propõe, portanto, justamente analisar e aprender a sistematizar o aparente caos linguístico existente em razão das variantes linguísticas. Essa sistematização é permitida porque, mesmo diante da diversidade dialetal existente em uma comunidade, os moradores dessa comunidade se comunicam e interagem. Conforme contribui Meillet (apud CALVET, 2002, p. 16): "Por ser a língua um fato social resulta que a linguística é uma ciência social, e o único elemento variável ao qual se pode recorrer para dar conta da variação linguística é a mudança social".

Como se pode notar, do ponto de vista do autor, toda e qualquer variação na língua é motivada estritamente por fatores sociais. $O$ ponto fundamental nessas abordagens, portanto, é a presença do componente social na análise linguística. Com efeito, a sociolinguística se ocupa da relação entre língua e sociedade e do estudo da estrutura e da evolução da linguagem dentro do contexto social da comunidade de fala, como citado anteriormente. Vemos também, que o fato de a variação ser inerente às línguas está intimamente relacionado à noção de heterogeneidade. 
Por sua vez, essa característica da língua recebe contribuições da teoria da sociolinguística variacionista ou variação linguística criada por William Labov. Este autor traz algumas considerações de sua teoria aplicada em seus estudos de variação nos Estados Unidos. Ele observa, no livro intitulado Padrões sociolinguísticos, que a variação linguística pode ocorrer por diferentes fatores sociais ou extralinguísticos, entre estes estão: idade, sexo, local e profissão dos sujeitos pesquisados.

Como não temos pretensão de retomar os diferentes conceitos de análise linguística, entretanto, à guisa de ilustração, é importante lembrar que o modelo teórico-metodológico da Sociolinguística Variacionista, também denominada Sociolinguística Quantitativa, por operar com números e tratamento estatístico dos dados coletados, criado por William Labov, contribuiu e contribui para um modelo de análise que possibilita a sistematização da variação existente na língua falada.

Reconhecidamente, podemos afirmar que a Sociolinguística permitiu, assim, o estudo científico de fatos linguísticos excluídos até então do campo dos estudos da linguagem, devido à sua diversidade e consequente dificuldade de apreensão. Através de pesquisas de campo, a Sociolinguística registra, descreve e analisa sistematicamente diferentes falares, elegendo, assim, a variedade linguística como seu objeto de estudo. Trabalha-se com o falanteouvinte real, em situações reais de linguagem.

De fato, os informantes escolhidos geralmente estão entre as pessoas nascidas e criadas na comunidade a ser estudada ou aqueles que vivem nela desde os cinco anos de idade. Segundo Guy e Zilles (2007), uma das melhores formas de garantir que haja representatividade é o uso de uma amostra aleatória que dê a cada informante ou dado potencial existente na população total igual probabilidade de serem incluídos na amostra. Para se estimar a relação entre amostra e o universo de onde foi retirada usam-se as medidas de significância, comuns em pesquisas de base quantitativa ${ }^{1}$.

Embora com metodologia bem delimitada, a Sociolinguística Variacionista baseia-se em pressupostos teóricos que permitem ver regularidade e sistematicidade por trás do aparente caos da comunicação no

${ }^{1}$ Com a finalidade de aprofundar no instrumental de análise quantitativa na sociolinguística variacionista ver Guy e Zilles (2007). 
dia a dia, procurando demonstrar como uma variante se implementa na língua ou desaparece. Nesse sentido, a análise sociolinguística enfoca fundamentalmente o processo de interação fala/sociedade, justificando-se pela necessidade de compreender os fatores que possam influenciar a operação de uma ou de outra variante, na busca de estabelecer uma sistematização ao processo de variação linguística.

Por esse caminho, este estudo provém do interesse básico de descrever o português brasileiro, fazendo a análise da variação semântico-lexical de natureza diatópica. O resultado, portanto, consiste no mapeamento de formas variantes nos níveis de descrição lexical. Para proceder às investigações, foram tomados como base os princípios e o método de investigação científica da pesquisa dialetológica numa nova perspectiva, a de identificar os fatores sociais que condicionam a diversidade do falar numa determinada comunidade, adotando-se, assim, a contribuição da Sociolinguística no sentido de considerar, neste estudo, que as alternâncias de uso (ou variação) são influenciadas também por fatores extralinguísticos, como idade, gênero do falante e escolaridade, como afirma Brandão (2005, p. 26):

... torna-se imperativo incluir, entre os critérios de escolha dos indivíduos que servirão de informantes para a formação do corpus de um Atlas lingüístico, variáveis como idade, sexo, nível de instrução, ou mesmo situação socioeconômica, a fim de que se revelem ao máximo as peculiaridades do sistema dialetal focalizado e se possam melhor conhecer os condicionamentos socioculturais que presidem à distribuição geográfica dos fenômenos lingüísticas.

Como mostram Cardoso e Ferreira (1994), a dialetologia é uma ciência que brotou nos fins do século XIX, e que demonstrou - e demonstra até os dias de hoje - um maior interesse pelos dialetos regionais, rurais e sua distribuição e intercomparação. Assim, por muito tempo, antes mesmo de a sociolinguística ter se firmado como um ramo da ciência da linguagem, a dialetologia já se utilizava de recursos interpretativos que passaram a ser posteriormente definidos como da sociolinguística. Para as autoras, são determinadas quatro etapas principais que devem ser observadas na pesquisa dialetal: preparação da pesquisa; execução dos inquéritos; explicitação e análise dos materiais recolhidos e divulgação dos resultados obtidos. 
Observa-se, nesse sentido, a inter-relação entre os dois campos de investigação linguística, a Dialetologia e a Sociolinguística. Mostrando a relação entre as duas disciplinas, Cardoso e Ferreira (1994, p. 19) afirmam:

$\mathrm{Na}$ verdade, definir objetivo e metas dos vários ramos da ciência da linguagem, como, aliás, em qualquer ciência, é sempre muito difícil porque são fluidos ou pouco nítidos esses limites, mais fluidos e pouco nítidos se tornam quando se fala em dialetologia e sociolingüística que têm - ambas - como objetivo maior o estudo da diversidade da língua dentro de uma perspectiva sincrônica e concretizada nos atos da fala.

O reconhecimento dessas interfaces faz-nos compreender a inter-relação entre esses dois campos de estudos. Ou seja, podemos dizer que os estudos dialetológicos e sociolinguísticos são indissociáveis, onde um pressupõe o outro. Apesar do alto grau de interseção entre as duas disciplinas, deve-se ressaltar a diferença entre seus objetivos e método de investigação para que se possa distingui-las. A Dialetologia preocupa-se, essencialmente, em estabelecer limites geográficos de certos usos linguísticos, enquanto a Sociolinguística tem como objetivo identificar processos linguísticos de variação e mudança, bem como localizar fronteiras sociais da língua em uso. Porém, observa Brandão (2005, p. 17) que o "estudo da modalidade oral do português do Brasil, portanto, não se confina nos limites da dialetologia e da sociolingüística; ao contrário, ultrapassa-os, amparando-se, também, em pressupostos históricos".

Compreendendo, então, o mecanismo sociolinguístico como subjacente à dialetologia - numa nova perspectiva - e à distribuição geográfica dos usos linguísticos, foram adotados, para a realização do estudo sobre a diversidade linguística nessa região da Amazônia, os princípios teóricos da Geografia Linguística como método científico da dialetologia, resultando no mapeamento de formas variantes nos níveis de descrição semânitico-lexical. 


\subsection{A Geografia Linguística ou Geolinguística}

A Geolinguística, por sua vez, é a parte da Dialetologia que se ocupa em localizar e registrar as variações das línguas. É um método cartográfico desenvolvido por dialetólogos que tinham por objetivo registrar e comparar os resultados das pesquisas linguísticas em localidades diferentes.

Nessa perspectiva, a base conceitual desta pesquisa são os estudos fundamentados nos princípios teórico-metodológicos da Geolinguística, princípios esses coerentes e condizentes com a meta que se persegue, pois, segundo Coseriu (1982, p. 79),

A Geolingüística pressupõe o registro em mapas especiais de um número relativamente elevado de formas lingüísticas (fônicas, lexicais ou gramaticais) comprovadas mediante pesquisa direta e unitária numa rede de pontos de um determinado território, ou que, pelo menos, tem em conta a distribuição das formas no espaço geográfico correspondente à língua, às línguas, aos dialetos ou aos falares estudados.

Sem dúvida, mais recentemente, a Geografia Linguística foi aos poucos se aperfeiçoando e, modernamente, procura retratar não apenas dados linguísticos, mas extralinguísticos e ainda peculiaridades etnológicas de cada área dialetal, seja rural, seja urbana, numa visão multidialetal. Entretanto, a preocupação com outras variáveis, que não apenas a diatópica, há muito se faz presente no âmbito da dialetologia. Cardoso (2010, p. 19) ratifica:

... idade, gênero, grau de escolaridade, profissão, inserção social constituem variáveis que, na perseguição de aspectos socioculturais, a dialetologia busca controlar e identificar. A apresentação cartográfica de tais dados põe lado a lado a informação diatópica e a informação sociolinguística.

Dessa forma, entendemos que os falantes de uma língua sobrevivem e se articulam em sociedade e que a relação entre língua e sociedade não é por acaso. $\mathrm{O}$ uso alternativo de formas linguísticas também não ocorre 
ocasionalmente; supõe-se, neste caso, a influência de fatores estruturais, sociais e regionais que justifiquem as alternâncias de uso.

Essa relevância atribuída à Geolinguística pode ser observada à luz de sua dimensão do conhecimento linguístico, dentro de um determinado contexto, por isso se revela significativa, na medida em que contribui para o registro da memória de comunidades linguísticas brasileiras, como neste estudo semântico-lexical da fala da zona rural do nordeste paraense, evidenciado pelo Questionário Semântico-Lexical (COMITÊ NACIONAL, 2001), instrumento largamente utilizado na produção de dados, como os relativos a esta investigação, entre estes, identificação, registro e tabulação das ocorrências de natureza semântica.

Apesar de o nosso pluralismo cultural ser evidenciado por escritores regionalistas através de obras que retratam peculiaridades etnográficas e linguísticas, é necessária a elaboração de um Atlas linguístico que retrate a realidade da língua falada no Brasil, desejo retratado há décadas nas palavras de Silva Neto (1955, p. 5): “No Brasil, [...] é preciso, antes de mais nada, criar mentalidade dialetológica, preparando um ambiente favorável às pesquisas de campo".

Essa proposição inovadora dos estudos dialetais, mostrada desde o século passado, como vimos, tendo por suporte o método geolinguístico, empreende pesquisas de campo, na atualidade, registrando os dialetos e os falares por meio da aplicação de um questionário previamente elaborado a determinados sujeitos e pela elaboração de cartas, onde as respostas são registradas e pelas quais podemos, então, obter o mapeamento das variantes linguísticas. Essas cartas registram diversos fenômenos que nos permitem compreender melhor alguns fatores da história da língua, como as migrações de palavras de uma região a outra, os centros de irradiações, e muitas outras, dando-nos uma visão de conjunto que por outro método seria difícil conseguir.

A rigor, o primeiro passo é a escolha dos pontos. Chamamos de ponto linguístico a cada uma das localidades em que se recolhem os dados de natureza linguística. Em seguida, é a escolha do instrumento para a coleta de dados. As lexias obtidas como respostas dos sujeitos constituem o material de análise para nossa pesquisa. Segundo o Comitê realizador do Projeto ALiB, a seleção dos itens do QSL tem como objetivo documentar o registro 
coloquial do falante, procurando retratar as formas de emprego mais gerais da comunidade pesquisada, sem, com isso, priorizar regionalismos, arcaísmos ou linguagens especiais de certos grupos. Logo depois, passamos à escolha dos sujeitos. Baseando, aqui, nos trabalhos de Silva Neto (1955) e nas postulações do projeto ALiB. Após as entrevistas, ouvimos as gravações e fazemos as transcrições grafemáticas das falas dos sujeitos. Retratamos as variáveis semântico-lexicais através de uma análise quantitativa para as posteriores análises semântico-lexicais e elaboração das tabelas com as lexias para chegar à meta de elaboração dos atlas.

Outro ponto importante a considerar, quanto ao trabalho geolinguístico, encontramos nas palavras de Cardoso e Ferreira (1994 p. 1920):

A dialetologia não deve ser confundida com a geografia lingüística ou geolingüística [...] Todavia, os Atlas lingüísticos sempre se constituíram em meta ou aspiração dos dialetólogos. [...] Na realidade, a publicação de um Atlas significa o final de um e o início de um, obra aberta aos estudos dialetais, os mais distintos; é um documento irrefutável de uma realidade da língua, diversificada nos seus vários níveis.

Com esta afirmação, as autoras procuram reafirmar a autenticidade dos atlas como fontes de registros linguísticos regionais, tendo em vista que fornecem dados para que se aprofunde a análise dos dialetos regionais e, através dessa análise, a realidade linguística do país se torne mais conhecida.

\subsection{Atlas Linguístico do Brasil}

Brandão (2005), considerando a constituição dos atlas na atualidade, afirma ser urgente que se amplie e enfrente a descrição do funcionamento da língua falada no Brasil, no plano geográfico, cujo procedimento mais adequado, para se pesquisar nesta amplitude continental, parece ser o que propõe a Dialetologia - estudo relativo às questões diatópicas - cujo método, o Geolinguístico, cartografa. Este método foi usado pela primeira vez por Jules Gilliéron, na pesquisa que resultou no Atlas Linguístico da França (ALF), primeiro trabalho nessa área reconhecidamente elaborado com bases científicas. A esse respeito, corrobora Razky (2005, p. 212): 
A realidade da variação lingüística revelada por meio desses atlas e dos estudos sociolingüísticos desenvolvidos no Brasil constituem hoje um acervo importante para diferentes áreas do conhecimento que tratam do homem, de seu meio e de sua fala.

Essa afirmação conduz ao entendimento de que a realidade do contexto social de cada indivíduo o capacita para fazer uso de sua linguagem adequadamente para se comunicar conforme a necessidade, a localidade e sua realidade de comunicação, uma vez que só há comunicação se houver interação social e, para que isso ocorra, é necessário que o falante se faça entender num processo comunicacional.

É nessa ótica que o $\mathrm{ALiB}^{2}$, coordenado pela pesquisadora Suzana Alice Cardoso é um dos projetos macros de dialetologia que objetiva realizar estudos dialetais abrangendo todo o território nacional. Em seu questionário contempla os diferentes aspectos linguísticos: fonológicos, morfológicos, sintáticos, semânticos e lexicais. O momento mais importante e que deu impulso para a construção do ALiB foi o Seminário "Caminhos e Perspectivas para a Geolingüística no Brasil” realizado na Universidade Federal da Bahia, em 1996. Segundo Cardoso (2010, p. 187), esse espaço foi favorável à construção desse projeto, pois "reuniu pesquisadores no campo da dialetologia, contando com a presença de todos os autores de atlas lingüísticos até àquela época já publicados". No entanto, Callou (2010, p. 33) esclarece:

A elaboração de um Atlas Linguístico no Brasil (ALiB), tarefa cogitada há mais de cinquenta anos, foi sendo adiada, entre outras razões, pela extensão territorial do país, pela assimetria da densidade demográfica e por falta de recursos humanos e financeiros, não obstante os esforços de Antenor Nascentes, Serafim da Silva Neto, Celso Cunha, Nelson Rossi. Só agora se torna uma realidade, a partir da iniciativa de Cardoso (2005), da UFBa, e de muitos outros pesquisadores de vários universidades brasileiras.

${ }^{2}$ O Decreto 30643, de 20 de março de 1952, definia como uma das finalidades da Comissão de Filologia da casa de Rui Barbosa a elaboração do Atlas Linguístico do Brasil. Disponível em: <http://migre.me/qsQ2N>. 
Assim, em 1996, constitui-se a equipe responsável pela concretização do Projeto ALiB. Atualmente, esse Projeto é integrado nacionalmente e conta com a participação de diversas Universidades Federais, cujos membros que formam o Comitê Nacional são: Suzana Alice Marcelino da Silva Cardoso, Diretora Presidente, da Universidade Federal da Bahia; Jacyra Andrade Mota, Diretora Executiva, da Universidade Federal da Bahia; e os Diretores Científicos Maria do Socorro Silva de Aragão, da Universidade Federal do Ceará/Universidade Federal da Paraíba; Vanderci de Andrade Aguilera, da Universidade Estadual de Londrina; Mário Roberto Lobuglio Zágari (in memorian), da Universidade Federal de Juiz de Fora; Walter Koch (in memorian), da Universidade Federal do Rio Grande do Sul; Aparecida Negri Isquerdo, da Universidade Federal de Mato Grosso do Sul; Abdelhak Razky, da Universidade Federal do Pará; Felício Wessling Margotti, da Universidade Federal de Santa Catarina; Cléo Vilson Altenhofen, da Universidade Federal do Rio Grande do Sul; Ana Paula Antunes Rocha, da Universidade Federal de Ouro Preto.

Esse Comitê instituiu os objetivos do Projeto ALiB e considerou a documentação de 250 localidades distribuídas por todo o território nacional e representativas das diversas regiões. Vale ressaltar que o Projeto ALiB já é uma realidade para professores e pesquisadores que se interessam por pesquisas no âmbito da descrição e análise de línguas e em conhecer a variação linguística do nosso português brasileiro. Os dois primeiros volumes do Atlas Linguístico do Brasil foram lançados pela Editora da UEL durante o III Congresso Internacional de Dialetologia e Sociolinguística (III CIDS), que aconteceu em outubro de 2014 em Londrina, no Paraná.

O projeto ALiB pauta-se nos fundamentos gerais da Geolinguística contemporânea, focalizando a variação espacial; no entanto, também se volta para as implicações de ordem social que não podem ser desconsideradas no estudo da descrição da língua. No campo da variação lexical, as maiores contribuições têm sido oferecidas a partir de estudos geolinguísticos de diferentes regiões do Brasil. Esses estudos, desde os trabalhos pioneiros do filólogo Antenor Nascentes, têm como propósito a elaboração de um Atlas Linguístico do Brasil, com o mapeamento das diferentes áreas linguísticas do português brasileiro. A partir daí vários pesquisadores se dedicaram a estudos geolinguísticos para testar empiricamente as suas hipóteses. Alguns 
desses estudos, como por exemplo, aqueles apresentados por Cardoso (2010), sobre o Nordeste brasileiro, têm apontado fortes coincidências de resultados com as linhas pioneiras de Nascentes (AGUILERA, 2005).

Nesse cenário, as variações linguísticas, no nível semântico-lexical, mostram-se como fonte inesgotável de pesquisa. São definidas como formas diferentes que permitem dizer a mesma coisa, ou seja, quando dois ou mais significantes têm o mesmo significado (conceito) e quando as diferenças que eles representam têm função outra, estilística ou social. Conforme Silva (2008, p. 24):

Se por um lado todo enunciado tem uma significação resultante de um conjunto de fatores ligados ao sistema lingüístico, por outro, o valor semântico total ou a realização plena da significação depende muito de fatores externos ao próprio sistema.

Veremos, pois, dentre os vários constituintes do sistema linguístico, apenas os que formam os campos semântico e lexical. Sendo correto lembrar que o léxico é o conjunto de palavras dispostas ao indivíduo com livre escolha para usá-lo ou empregá-lo no contexto em uso. Para Dubois et al. (1978, p. 364):

... como termo lingüístico geral a palavra léxico designa o conjunto das medidas que formam a língua de uma comunidade, de uma atividade humana, de um locutor, etc. por essa razão, léxico entra em diversos sistemas de oposição, conforme o modo pelo qual é considerado o conceito.

A partir dessa perspectiva, portanto, é relevante enfatizar que, na análise em questão, o léxico é entendido como um conjunto de unidades de uma comunidade linguística, previamente selecionada, de onde foram verificados alguns itens lexicais com o objetivo de conhecermos a norma estabelecida pelos falantes em um espaço geográfico.

Nesse contexto, é indiscutível, portanto, a importância do componente semântico-lexical de uma língua na interação social, uma vez que os falantes/ ouvintes recorrem a todo instante aos dados semântico-lexicais para expressar o mundo/espaço nessa interação social. Daí a razão do grande número de 
pesquisadores interessados, nas últimas décadas, por pesquisas das áreas da linguística, destacando mais a geolinguística. Nessa perspectiva, Santos (2009, p. 314) orienta a busca por mostrar os itens lexicais que constam dos estudos geolinguísticos e atlas linguísticos que são parte integrante da atividade linguística produtora de sentidos que se desenvolve em relação a um dado tempo histórico e no seio de uma comunidade linguística num determinado espaço.

\section{Instrumentos e Métodos de Pesquisa}

Com base nos fundamentos da Geolinguística, método cartográfico da Dialetologia, buscamos investigar a variação lexical na fala dos moradores de uma comunidade ribeirinha no nordeste da Amazônia paraense, localizada no município de São Miguel do Guamá, e compará-la às lexias propostas pelo ALiB (COMITÊ NACIONAL, 2001). Foram mapeadas a variação diatópica (espacial), diagenérica (sexo) e diageracional (faixa etária), resultando, portanto, em um trabalho pluridimensional, em outras palavras, com análise e resultados que contemple, simultaneamente, a variação em diferentes dimensões. A seleção dos informantes segue os critérios do ALiB, a saber: dois informantes do sexo masculino e dois do sexo feminino, com idade entre 18 e 30 anos e entre 50 a 75 anos, e escolaridade ensino fundamental incompleto.

Os informantes foram submetidos ao QSL, contendo 202 perguntas distribuídas em 14 itens temáticos; no entanto, para este estudo, considerouse apenas um item temático que denomina comportamento e convívio social. Nesse campo há 14 perguntas, das quais analisaremos 6, a saber ${ }^{3}$ :

136. Pessoa Tagarela;

138. Pessoa Sovina;

139. Mau pagador;

141. Marido enganado;

142. Prostituta;

144. Bêbado.

${ }^{3}$ Importa esclarecer que foi mantida a numeração original do ALiB/2001 no interior das ilustrações. 
Para o ponto de inquérito foi escolhida a comunidade ribeirinha Urucuriteua, localizada, como já dito anteriormente, no município de São Miguel do Guamá, como mostra a figura 1:

Figura 1 - Localização geográfica do Município de São Miguel do Guamá-PA

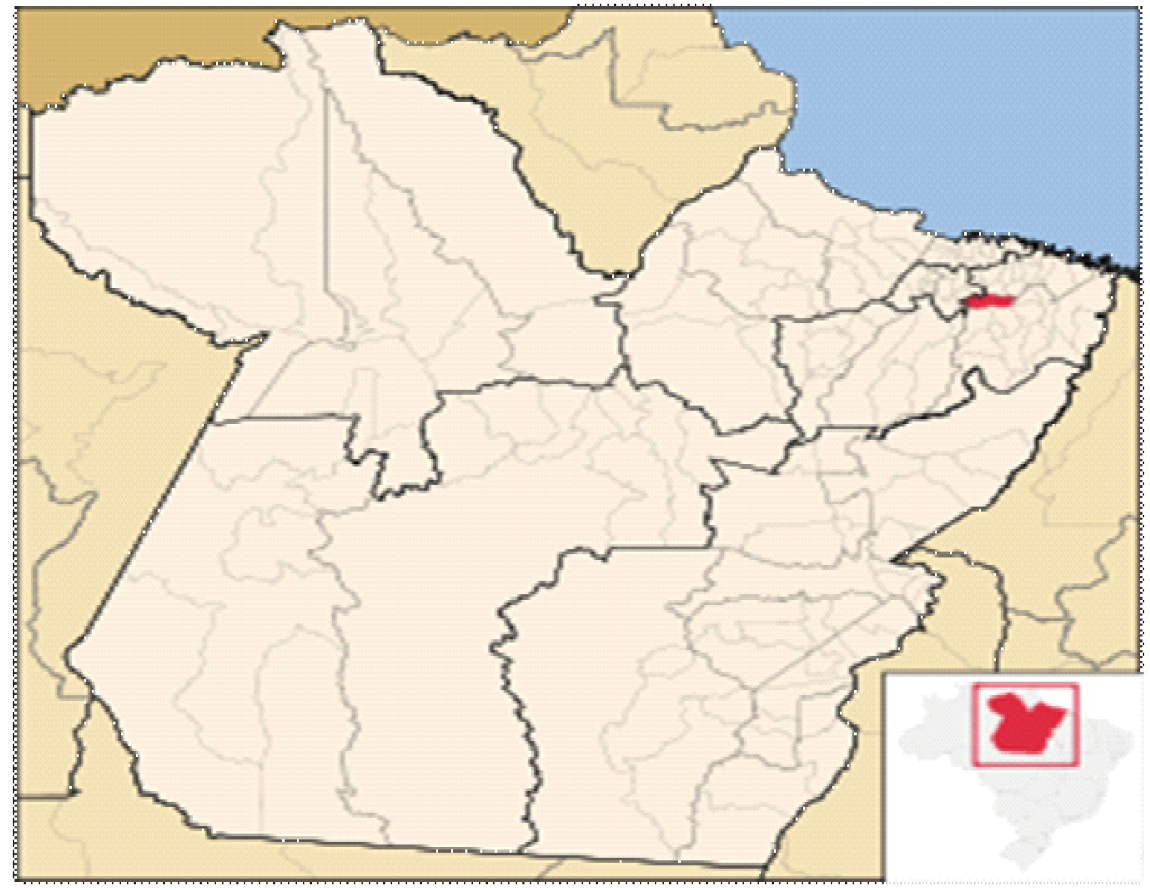

Fonte: IBGE, 2010.

\section{Apresentação e Análise dos Resultados}

Para orientar a leitura das cartas, temos os símbolos FA, FB, MA e $\mathrm{MB}$, que indicam o perfil dos informantes $(\mathrm{FA}=$ mulher de 18 a 30 anos; FB $=$ mulher de 50 a 72 anos; $\mathrm{MA}=$ homem de 18 a 30 anos e $\mathrm{MB}=$ homem de 50 a 75 anos). Cada variante encontra-se identificada por símbolos também, neste caso, marcadas por cores. Em relação ao perfil do informante, o símbolo marcado pela cruz $(+)$ indica a posição de cada um. 
Na Carta 1 (Anexo 1), a seguir, referente à questão 136 do QSL, registramos 4 variantes com a mesma recorrência e diferentes da proposta pelo ALiB: linguarudo, faladô, conversadêra e faladêra. Do ponto de vista da variação diageracional, a fala dos informantes da primeira faixa etária registrou as variantes linguarudo e faladô. As variantes conversadêra e faladêra se destacam nas respostas dos informantes de segunda faixa etária. E quanto à descrição diagenérica das quatro ocorrências dessa variante, todas foram registradas com a mesma frequência entre os informantes do sexo feminino e do masculino.

A Carta 2 (Anexo 2), mostra claramente duas ocorrências diferentes do proposto pelo ALiB, a saber: pão duru e mão di vaca. Mostra, também, quanto ao aspecto social, a predominância da variante pão duru na fala dos informantes de primeira faixa etária, e mão di vaca predominante na fala dos informantes de segunda faixa etária. Nesta ocorrência, portanto, temos uma considerável diferença entre a fala dos mais jovens para a fala dos mais velhos.

A Carta 3 (Anexo 3), relativa à questão 139 do QSL, é bastante produtiva, apresentando três variantes diferentes à proposta pelo ALiB. Chama a atenção o fato de, no aspecto diagenérico, a variante mau pagadô ter sido registrada na fala dos informantes masculinos, considerando aí forte variação na fala das mulheres, com as variantes inroladus e calotêro com igual frequência.

A Carta 4 (Anexo 4) apresenta quatro variantes lexicais diferentes das apresentadas pelo $\mathrm{ALiB}$, registradas no ponto de inquérito investigado: $e x$, chifrudo, corno e traídu, com a mesma frequência entre os informantes. Como se pode ver, os informantes apresentaram uma diversidade enorme quanto à variante marido enganado: corno e ex foram registrados na fala dos informantes do sexo feminino e chifrudo e traidu na fala dos informantes do sexo masculino.

Considerando-se a variante diatópica na Carta 5 (Anexo 5), referente à questão 142 do QSL, temos um registro expressivo de variantes, a saber: prostituta, piranha, safada, galinha.

Em relação à distribuição diagenérica e diageracional, verificamos que a variante prostituta chama a atenção, uma vez que é uma variante que coincide com a proposta pelo ALiB e aponta predominância na fala do informante de primeira faixa etária e do sexo feminino. Já para a segunda faixa etária são verificadas: safada e galinha, sendo que as variantes ocorrem com a mesma frequência na fala dos informantes tanto do sexo masculino quanto feminino. 
A Carta 6 (Anexo 6), elaborada a partir das respostas para a questão 144 do QSL, apresentou quatro variantes lexicais no total, todas diferentes das propostas pelo ALiB. São elas: pudim de cachaça, cachacero, viciadu e beberrão, sendo igual a ocorrência para cada variante.

Assim, quanto à distribuição diageracional, identificamos, na Carta 6, que as variantes mais conhecidas, como cachacero e beberrão, foram mencionadas pelos informantes do sexo masculino.

\section{Considerações Finais}

O registro da variação lexical na zona rural do nordeste paraense demonstrou que, em um espaço de interação, as palavras carregam entre si um enorme valor significativo, ampliando o universo configurativo da linguagem, estabelecendo parâmetros de produção de sentidos, caracterizando e enriquecendo situações de uso da língua. São responsáveis pela dinamicidade do universo do conhecimento, de maneira que se apresenta suscetível de mudanças dialetais, de acordo com o que o contexto exigir.

Essa pesquisa, de natureza lexical de um ponto linguístico, permitiu alcançarmos uma visão pluridimensional da língua falada do universo cultural da comunidade pesquisada, reconhecendo nela as suas influências geográficas e históricas, a ação do homem sobre a natureza e o seu perfil social, contribuindo para o conhecimento atual do português falado no Brasil.

Os dados demonstram, enfim, um elevado índice de lexias não coincidentes com as propostas pelo ALiB. O baixo percentual do número de lexias de maior frequência e não coincidentes pode conduzir, inicialmente, a inferirmos que não há, de fato, uma considerável diversidade semânticolexical entre os falantes localizados geograficamente nos extremos do Brasil. Através das cartas geolinguísticas, é possível visualizar a forma como ocorre o fenômeno da variação em nossa língua. 


\section{Anexos}

\section{Anexo 1 - Carta Linguística 1}

Item 136 - Pessoa Tagarela

... a pessoa que fala demais?

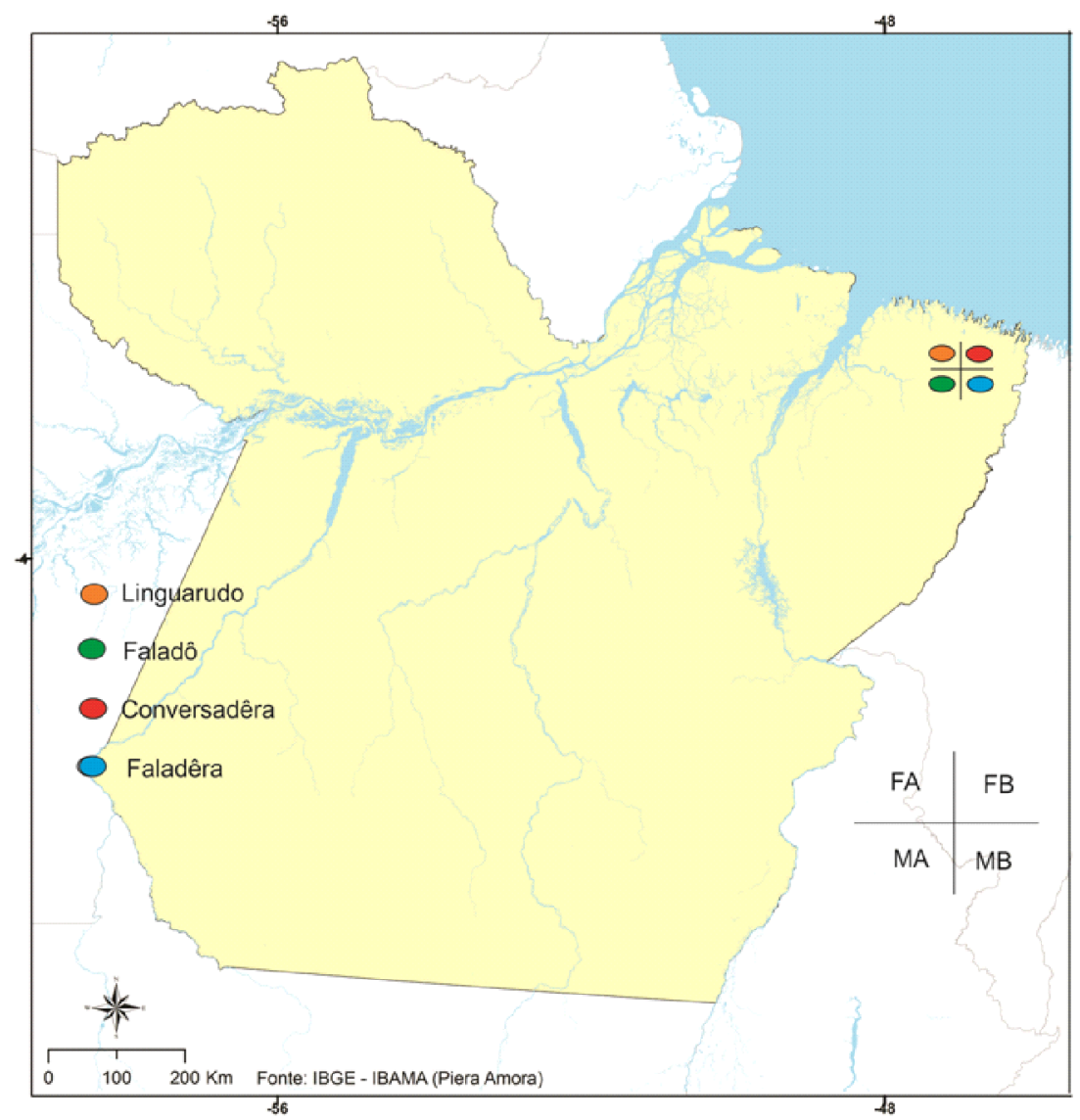

Fonte: A autora. 


\section{Anxo 2 - Carta Linguística 2}

\section{Item 138 - Pessoa Sovina}

... a pesśoà que não gosta de gastar o seu dinheiro e, às vezes, até passá dificuldade para não gastar?

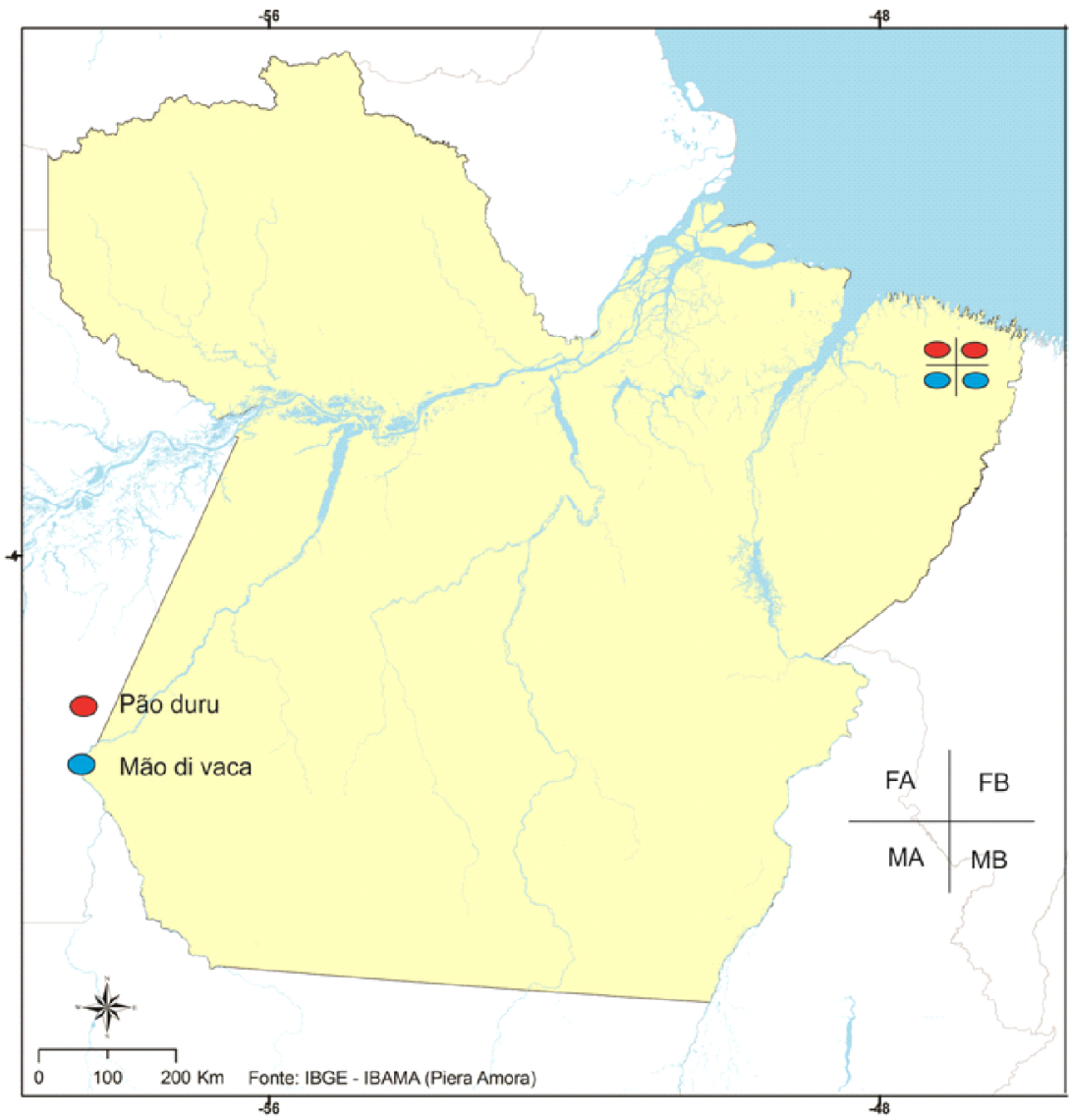

Fonte: A autora. 
Anexo 3 - Carta Linguística 3

Item 139 - Mau Pagador

... a pessoa que deixa suas contas penduradas?

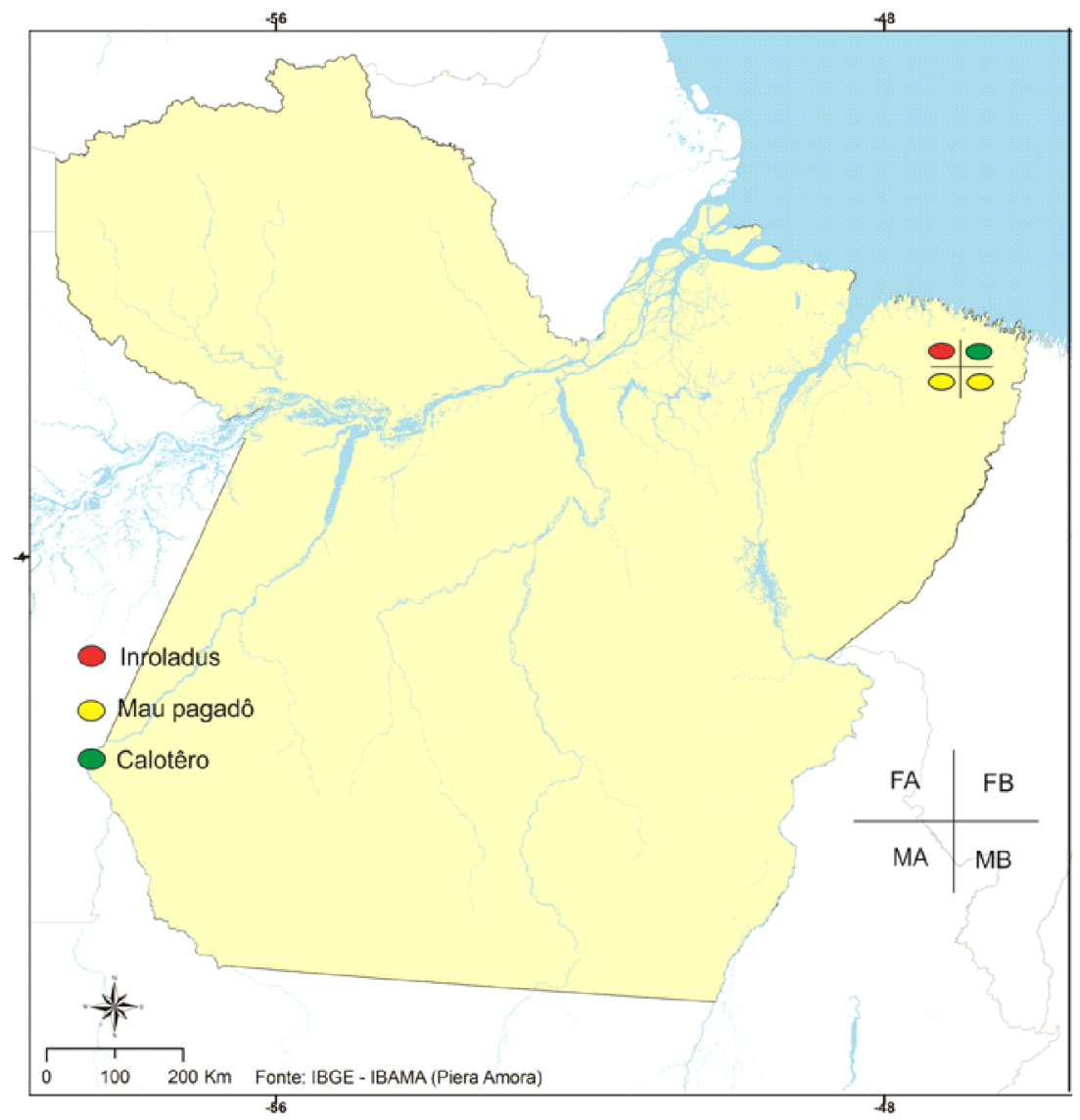

Fonte: A autora. 


\section{Anexo 4 - Carta Linguística 4}

Item 141 - Marido Enganado

... o marido que a mulher passa para trás com outro homem?

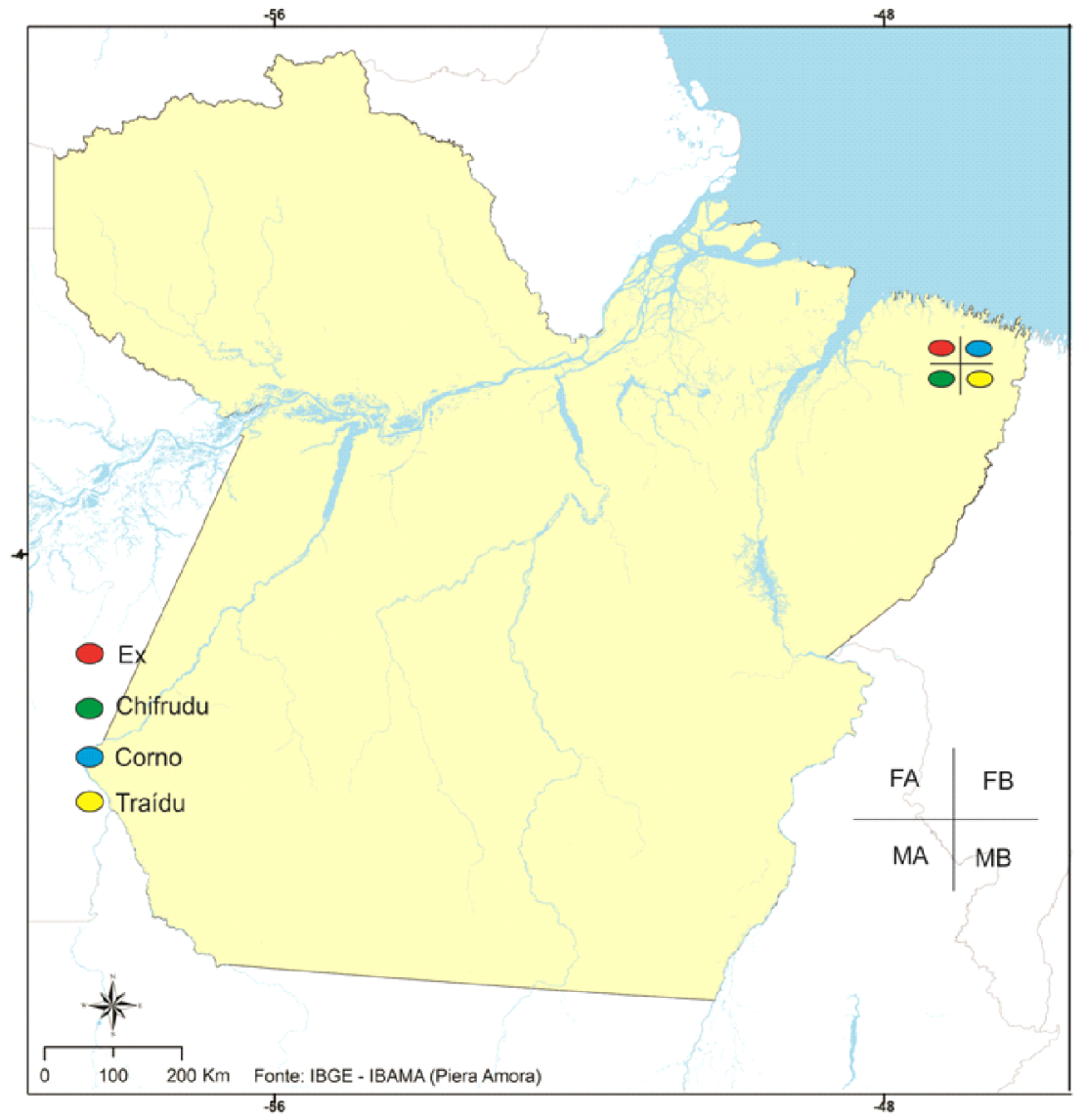

Fonte: A autora. 


\section{Anexo 5 - Carta Linguística 5}

Item 142 - Prostituta

... a mulher que se vende para qualquer homem?

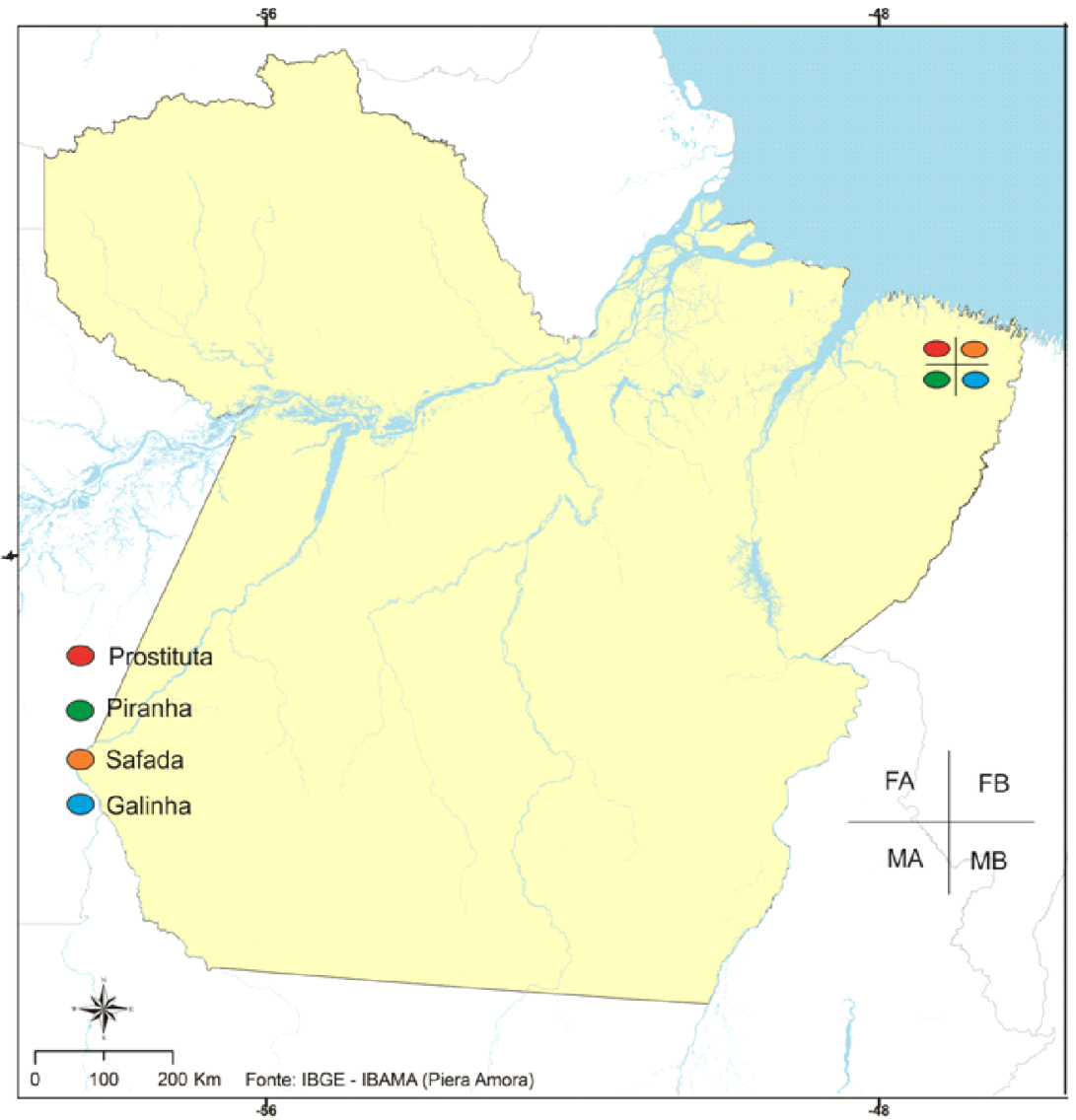

Fonte: A autora. 


\section{Anexo 6 - Carta Linguística 6}

Item 144 - Bêbado (Designações)

Que nomes dão a uma pessoa que bebeu demais?

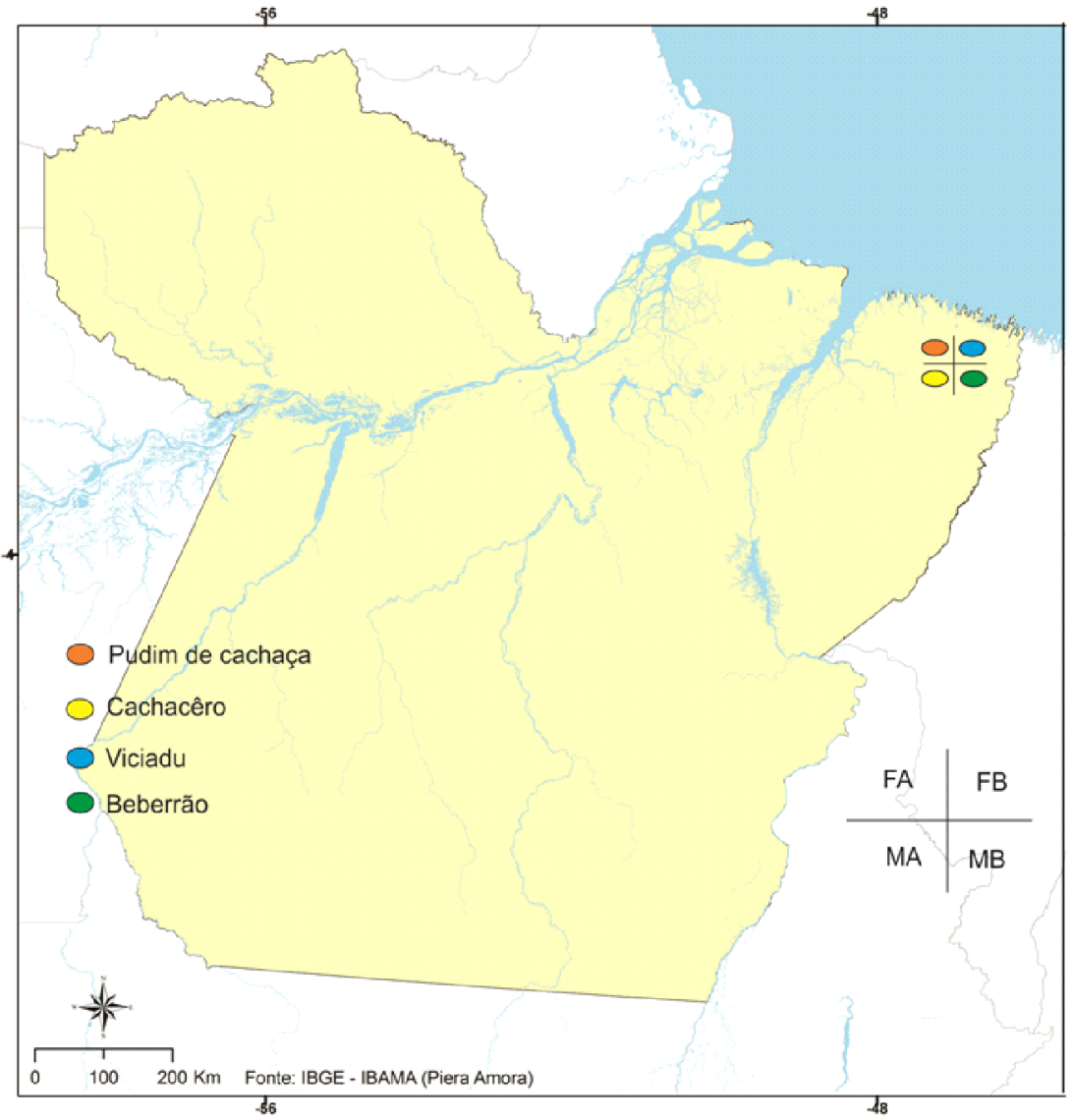

Fonte: A autora. 


\section{Referências}

AGUILERA, V. de A. O Atlas Lingüístico do Brasil: de "nascituro" a “adolescente". In: AGUILERA, V. de A. (Org.). A Geolingüística no Brasil: trilhas seguidas, caminhos a percorrer. Londrina: Eduel, 2005. p. 210-227.

BRANDÃO, S. F. A geografia lingüistica no Brasil. São Paulo: Ática, 2005.

CALLOU, D. Quando Dialetologia e Sociolinguística se encontram. Estudos Linguísticos e Literários, Salvador, n. 41, p. 29-48, jan./jun. 2010.

CALVET, L. J. Sociolingüistica: uma introdução crítica. Tradução Marcos Marcionilo. São Paulo: Parábola, 2002.

CARDOSO, S. A. M. Geolinguística: tradição e modernidade. São Paulo: Parábola, 2010.

CARDOSO, S. A. M.; FERREIRA, C. A dialetologia no Brasil. São Paulo: Contexto, 1994.

COMITÊ NACIONAL DO PROJETO ALIB. Atlas Lingüístico do Brasil. Questionários. Londrina: Eduel, 2001.

COSERIU, E. A geografia lingüística. In: COSERIU, E. O homem e sua linguagem. Tradução Carlos Alberto Fonseca e Mário Ferreira. Rio de Janeiro; São Paulo: Presença; USP, 1982. p. 79-116.

DUBOIS, J. et al. Dicionário de lingüística. São Paulo: Cultrix, 1978.

GUY, G. R.; ZILLES, A. M. S. Sociolingüistica quantitativa: instrumental de análise. São Paulo: Parábola, 2007.

INSTITUTO BRASILEIRO DE GEOGRAFIA E ESTATÍSTICA IBGE. Pará, São Miguel do Guamá: infográficos. Censo 2010. Disponível em: <http://migre.me/qsNs7>. Acesso em: 22 mar. 2014.

LABOV, W. Padrões sociolingüísticos. Tradução Marcos Bagno et al. São Paulo: Parábola, 2008. 
PROJETO ATLAS LINGUÍSTICO DO BRASIL. Disponível em: $<$ http://migre.me/qsOqY>.

RAZKY, A. Atlas Lingüístico Sonoro do Pará: uma nova perspectiva para a organização do corpus geolingüístico. In: AGUILERA, V. de A. (Org.). A Geolingüistica no Brasil: trilhas seguidas, caminhos a percorrer. Londrina: Eduel, 2005. p. 210-227.

SANTOS, I. P. Memória coletiva, Geolinguística e relações textuaisdiscursivas. In: SANTOS, J. B. C. dos. Sujeito e subjetividade: discursividades contemporâneas. Uberlândia: EDUFU, 2009. p. 337-347.

SILVA NETO, S. da. Guia para estudos dialectológicos. Florianópolis: PUC-Rio, 1955.

SILVA, M. do P. S. C. da (Org.). As interfaces dos estudos lingüísticos. 2. ed. Belém: UNAMA, 2008.

TARALLO, F. A pesquisa sociolingüistica. 8. ed. São Paulo: Ática, 2007.

Recebido em: 20/11/2014 Aceito: 03/04/2015 